\title{
Agentes produtivos e desenvolvimento: polo naval e capacidade de inovação no Rio Grande do Sul'
}

Sandro Ruduit Garcia ${ }^{2}$

\begin{abstract}
Resumo
O artigo tenta identificar novas dinâmicas de desenvolvimento econômico e social no Brasil, enfocando incentivos governamentais e de mercado à constituição de um polo de construção naval na cidade de Rio Grande, na segunda metade dos anos 2000. Analisa as respostas dos agentes produtivos em termos da expansão da capacidade de inovação, traduzida em externalidades criadas pela aglomeração espacial de empresas, nas capacidades dos recursos humanos e, especialmente, em iniciativas de universidades do estado do Rio Grande do Sul. A hipótese em discussão é a de que os agentes produtivos tenderiam a responder a novos estímulos governamentais e de mercado com a criação de redes de colaboração aplicadas à produção de conhecimentos específicos e de inovação. Os dados resultam de entrevistas com gestores de estaleiros, do porto e de universidades realizadas no primeiro semestre de 201 I, em Rio Grande, Pelotas e Porto Alegre, assim como de diferentes fontes secundárias (documentos e bases estatísticas).
\end{abstract}

Palavras-chave: Desenvolvimento econômico. Inovação. Indústria naval.

I Este artigo foi apresentado no XV Congresso Brasileiro de Sociologia, GT Sociologia Econômica, expressando resultados preliminares do projeto de pesquisa Aglomerações industriais, tecnologia e trabalho: efeitos sociais do polo naval de Rio Grande, coordenado pelo autor e financiado pelo CNPq. A pesquisa contou com a valiosa colaboração dos bolsistas de iniciação científica Gabriella Rocha de Freitas e Rodrigo Foresta Wolffenbüttel.

2 Doutor em Sociologia e professor adjunto no Departamento de Sociologia e no Programa de Pós-graduação em Sociologia da Universidade Federal do Rio Grande do Sul (UFRGS), Porto Alegre, Brasil. É autor de artigos publicados nas revistas Sociologias (UFRGS, 2010), Revista Brasileira de Ciências Sociais (Impresso) (2009), Civitas (Porto Alegre, 2007), entre outras. É autor da obra Global e Local: o polo automobilístico de Gravataí (Annablume, 2009).E-mail: sandro.ruduit@ufrgs.br. 


\section{Introdução}

Os países emergentes deparam-se, nesta segunda década do século 21, com novas janelas de oportunidades ao desenvolvimento de suas economias e sociedades. Mudanças importantes nas regras das relaçóes de troca internacionais, na organização e na dinâmica dos sistemas produtivos e nos valores e crenças de agentes e comunidades têm sido registradas, na literatura sociológica, pelos conceitos de globalização (THERBORN, 2000), informacionalismo (CASTELLS, 1999) e risco (GIDDENS, 2010). Sem entrar em detalhes sobre essa literatura, que é vasta e já bastante conhecida, interessa chamar a atenção para o fato de que tais mudanças estão a requerer novas estratégias institucionais e a atuar na orientaçấo dos agentes produtivos no sentido de privilegiar o conhecimento e a inovação como motores da vida econômica. Esse processo é bastante conhecido no que se refere à realidade dos países altamente industrializados, com instituiçóes e mercados maduros e com uma longa e consolidada trajetória de atividades de inovação pelos agentes produtivos. Porém, é ainda escassa a literatura sobre essas novas dinâmicas no contexto de economias e sociedades emergentes. Neste artigo, tenta-se melhor conhecer aspectos dessas mudanças nas regras e dinâmicas de desenvolvimento econômico e social no contexto da realidade do Brasil. Essa busca orienta-se pela seguinte indagação: Como agentes sociais imersos em relaçóes localmente situadas reagiriam às recentes mudanças nas regras de desenvolvimento econômico?

Ao considerarem-se contribuições e limites de abordagens bastante influentes sobre o problema, como a abordagem das relaçóes centro-periferia no sistema mundial e a dos sistemas de inovaçáo, busca-se reconhecer (e melhor precisar) os mecanismos institucionais (governamentais e de mercado) e os arranjos sócio-organizacionais mobilizados pelos agentes sociais na produçáo de inovação nesse novo contexto de desenvolvimento econômico. A hipótese em discussão é que os agentes produtivos tenderiam a responder aos novos estímulos governamentais e de mercado com a criação de redes de colaboração aplicadas à produção de conhecimentos específicos e de inovação. Supóe-se que a tecedura de redes pelos agentes seria um meio para acessar e mobilizar recursos relevantes para a capacidade de inovação, envolvendo uma complexa e habilidosa conjugação entre conhecimentos tácitos e codificados, próximos ou distantes, com vistas ao aproveitamento de janelas de oportunidades ao desenvolvimento. 
Nessa discussão, o artigo vale-se de contribuições intelectuais que se voltam para a capacidade de agência dos atores sociais (FLIGSTEIN, 2001; GIDDENS, 2003; SWEDBERG, 2009). Parte-se do pressuposto de que, a despeito da desigual distribuição de recursos e da força de valores e crenças na reprodução da vida social, os agentes seriam capazes não apenas de identificar e de mobilizar, ativa e habilmente, recursos importantes para a realizaçáo de seus interesses, como também de produzir novas redes de interação e significado compartilhadas por atores com interesses diversos, criando-se novas experiências e mesmo instituiçôes. Os interesses seriam socialmente definidos, assim como dependeriam de adequadas relaçóes e instituiçóes sociais para sua realização. Ademais, agentes governamentais têm o poder, não trivial, de criar condiçóes ao desencadeamento de episódios e mudanças favoráveis à realização desses interesses dos agentes produtivos.

O Brasil torna-se um valioso laboratório para se investigarem essas recentes mudanças nas regras de desenvolvimento econômico e social. $\mathrm{O}$ país acha-se desafiado a superar heranças do modelo de substituição de importaçôes, e a simples exportação de commodities (fala-se, hoje, em substituição de exportaçóes), esforçando-se em formular novos tipos de incentivos e açóes de política industrial e tecnológica, para favorecer a criação de conhecimentos e a capacidade de inovação (BARROS; GIAMBIAGI, 2008, 2009; CASTRO et al., 2005; VELLOSO, 2008)3 ${ }^{3}$. O que vem ocorrendo em torno das descobertas de petróleo e gás natural na camada geológica do pré-sal na costa marítima brasileira torna-se ilustrativo sobre mudanças na estratégia de desenvolvimento do país. Caberia destacar que as novas plataformas e embarcaçóes de apoio para a exploraçáo do pré-sal requerem tecnologia distinta daquela atualmente disponível, uma vez que se trata de águas mais profundas e frias, de solo mais salinizado e corrosivo, de localizaçáo mais distante do continente e de petróleo mais pesado e ácido. Isso constitui uma preciosa janela de oportunidade ao desenvolvimento de conhecimentos específicos e de inovaçóes de diferentes tipos pelo Brasil. Ademais, há que se considerar que o mercado de embarcaçóes e plataformas marítimas torna-se relevante para o país não somente pela nova demanda interna, mas também pelo crescimento da

3 São exemplos expressivos desse esforço, no âmbito do governo federal, a criação dos Fundos Setoriais, em 1998, a Política Industrial e de Desenvolvimento Científico e Tecnológico (PIDCT), em 2003, a Política de Desenvolvimento Produtivo (PDP), no ano de 2008, e o Programa Ciência Sem Fronteiras, de 2011 . 
demanda internacional, nos anos 2000, em razão do interesse na exploração de petróleo em alto mar relacionado à elevaçáo dos seus preços. Tudo isso ocorre em meio às novas pressóes internacionais por segurança energética e por novas responsabilidades diante de riscos ambientais, amplificando a necessidade de inovaçôes no preciso manuseio desse recurso natural.

Entende-se que essa nova conjuntura econômica e industrial suscita dúvidas sobre a capacidade explicativa de conceitos e argumentos informados pela ideia de desenvolvimento dependente no contexto de imposições nas relaçóes centro-periferia, com a simples importação de pacotes tecnológicos, como ocorria no passado. Assim como sobre a existência prévia de instituiçóes governamentais, sistêmica e evolutivamente articuladas, capazes de direcionar e realizar os interesses dos agentes produtivos, como se verifica em países de industrialização adiantada. Esses limites conceituais desafiam a imaginação sociológica a realizar um sério esforço teórico e empírico no sentido de tentar representar intelectualmente de forma mais precisa as particularidades do que ocorre, hoje, em países emergentes, como no caso do Brasil. Parece que, especialmente no que se refere ao caso em estudo, indagar sobre como se constituem interesses dos agentes em um novo contexto econômico e social seria tâo significativo sociologicamente quanto perquirir sobre mecanismos de coordenação e conflitos entre interesses diversos.

$\mathrm{O}$ artigo tem por objetivo analisar aspectos da conduta dos agentes em meio a essas mudanças nas regras e dinâmicas de desenvolvimento econômico e social, enfocando incentivos governamentais e de mercado à constituição de um polo de construçáo naval na cidade de Rio Grande na segunda metade dos anos 2000. Além disso, analisar as respostas dos agentes produtivos em termos da expansão da capacidade de inovação, traduzida em externalidades criadas pela aglomeraçáo espacial de empresas, nas capacidades dos recursos humanos e, especialmente, em iniciativas de universidades do estado do Rio Grande do Sul. Trata-se, pois, de identificar novos estímulos de mercado e incentivos governamentais à produção de conhecimentos específicos e de inovação nessa indústria, e as diferentes respostas e arranjos dos agentes produtivos, considerando-se seus interesses, valores e recursos disponíveis.

Os dados resultam de seis entrevistas, com roteiro semiestruturado, realizadas no primeiro semestre de 2011, em Rio Grande, Pelotas e Porto Alegre, com gestores de estaleiros e do porto relacionados ao polo e com pesquisadores 
de universidades envolvidos em atividades de interação com as indústrias em estudo, assim como de acesso a diferentes fontes secundárias: Relatório Anual de Informaçóes Sociais (RAIS/MTE), editais (CNPq; FINEP; IPEA; BNDES; Prominp), relatórios (SINAVAL; SOBENA; Petrobras), legislação e outros documentos pertinentes sobre regulaçáo e incentivos aos setores naval e petrolífero no Brasil, além de informaçóes obtidas em jornais locais.

\section{Argumentos recentes sobre desenvolvimento econômico}

$\mathrm{Na}$ conhecida e influente formulaçáo de Castells (1999), o industrialismo - processo de desenvolvimento orientado pelo simples crescimento da economia e pela maximização da produção - cederia o passo para o informacionalismo - orientado pelo desenvolvimento tecnológico e pelo acúmulo de conhecimentos - como referência dominante dos processos de desenvolvimento econômico e social, no contexto da economia global. Afirma Castells: "o que é específico ao modo informacional de desenvolvimento é a ação de conhecimentos sobre os próprios conhecimentos como principal fonte de produtividade" (1999, p. 35). Isso vai bem além da redutora dicotomia entre indústria e serviços no empuxe ao desenvolvimento, como proposto nas formulaçóes sobre pós-industrialismo. Mais importante do que o setor econômico da firma, seria a distinção entre níveis de intensidade de uso de conhecimento e de aplicaçáo tecnológica envolvidos na atividade produtiva.

Segundo Castells (1999, p. 419), o sistema industrial expressaria uma nova articulaçáo da dinâmica local e global, pois "o que resta como lógica característica da nova localização industrial é sua descontinuidade geográfica, paradoxalmente formada por complexos territoriais de produção", superando-se a antiga polarizaçáo entre produção de alta tecnologia no centro e fabricação de baixo custo na periferia. A capacidade de criar conhecimento específico e inovação para todo o sistema econômico dependeria, ao mesmo tempo, de proximidade espacial e de conexão às cadeias e mercados globais, colocando em xeque antigas estratégias de desenvolvimento - protecionismo, uso extensivo de mão de obra não qualificada, importação de tecnologias, incentivos focados na grande empresa - que se tornariam inadequadas para os mecanismos de promoçáo da produtividade e da competitividade no mundo globalizado.

De fato, a produção científica recente sobre diferentes aspectos das dinâmicas de desenvolvimento econômico (ARBIX, 2010; ARIFFIN; FIGUEIREDO, 2008; GUIDELLI; BRESCIANI, 2008; GUILLÉN; 
GARCIA-CANAL, 2009; KIM, 2005; NEGRI; SALERNO, 2005; OECD, 2002; POWELL; SNELLMAN, 2004; SALERNO, 2010) tem chamado a atenção para os efeitos positivos da capacidade de criação de conhecimentos e de sua transformação em inovações na economia e na sociedade. São exemplos a maior competitividade e produtividade nas organizaçôes, a geraçáo de melhores empregos, ambientes de trabalho mais estimulantes, maior inserção internacional das empresas e criação de artefatos e de processos de produção ambientalmente responsáveis, a despeito da criaçáo de novas dinâmicas de desigualdade no sistema produtivo e social. Ao mesmo tempo, essa literatura alerta, porém, sobre o imenso desafio que isso representaria em termos da mudança (ou até da ruptura) da cultura produtiva e empresarial e das instituiçóes economicamente relevantes. Isso seria especialmente verdadeiro no caso de países emergentes habituados à importação de pacotes tecnológicos, deixando, muitas vezes, de aproveitar-se de janelas de oportunidades que hoje se abrem no sistema global, no sentido de criar, produzir e intercambiar produtos de conteúdo tecnológico e de maior valor agregado.

Nesses novos arranjos e conjunturas de desenvolvimento econômico, o próprio conceito de inovação e a forma de sua apreensão têm sido rediscutidos. No passado, a inovação era reduzida ao novo produto, à grande descoberta ou à fronteira tecnológica (inovação radical, medida por patentes); em geral, os incentivos focalizavam a firma isolada, especialmente a grande empresa multinacional. No debate atual, a inovação passa a ser concebida em sentido amplo (como processo, modelos de negócio, logística, organização, produtos e tecnologia), reconhecendo-se o valor da chamada inovação incremental. Ademais, essa literatura recente tem mostrado que a produção de novo conhecimento e sua transformação em inovação é, hoje, um processo muito mais rápido e interativo do que no passado, dependendo de ambientes sociais e institucionais que favoreçam o fluxo de ideias e informaçóes entre diferentes tipos de agentes. Nesses termos, tem-se modificado, também, o modo de apreensão do fenômeno, tentando-se captar sua extensão, em especial nas economias emergentes. A literatura tem se utilizado de novos indicadores, buscando identificar a atividade inovativa e as capacidades de inovação de uma economia, destacando-se: a) a interação entre firmas; b) a disponibilidade e uso de recursos humanos qualificados; e c) as relaçóes entre universidades e indústria. 
Desde as formulaçôes de Alfred Marshall, sabe-se que a interação e a colaboração em aglomerações de firmas geram externalidades, criando-se não apenas a redução de custos de transação, mas também possibilidades de circulação de conhecimentos e o estímulo à criatividade. Nesse sentido, fala-se, mais recentemente, nas possibilidades de meios inovadores. Afirma Maillat (2002, p. 10):

a localização das atividades não é mais fundada sobre a simples utilização de recursos locais pré-existentes, mas sobre a inserção do estabelecimento no seu meio ambiente de implantação, para aí estabelecer relações de colaboração e contribuir assim para o seu enriquecimento e desenvolvimento em recursos específicos.

O meio inovador seria definido como "um conjunto territorial no qual as interaçóes entre os agentes econômicos desenvolvem-se náo só pela aprendizagem que fazem das transaçóes multilaterais, geradoras de externalidades específicas à inovação, como pela convergência das aprendizagens para formas cada vez mais aperfeiçoadas de gestão em comum dos recursos" (MAILLAT, 2002, p. 14).

Ramella e Trigilia (2009) argumentam, com base em um ilustrativo estudo sobre inovação em empresas italianas, que nas atuais condiçóes de desenvolvimento econômico as firmas tenderiam a assumir uma posiçáa ativa com relação à identificação e mobilização de recursos relevantes para atividades inovativas, envolvendo capacidades e habilidades desses agentes no sentido de explorar oportunidades. Nesse caso, as empresas valer-se-iam não apenas de seus recursos internos (em geral, insuficientes para inovar), mas também buscariam complementaridades no ambiente, a fim de realizar seu interesse em inovar. Isso ocorreria mediante a tecedura de redes de colaboração com outros agentes, presentes tanto no território quanto fora dele. As parcerias com vistas à inovação não se limitariam às fronteiras locais/regionais ("laços fortes" que propiciariam o compartilhamento de conhecimento tácito), mas constituiriam também redes de longo alcance ("laços fracos" que permitiriam o acesso a novo conhecimento codificado). Contudo, isso dependeria da existência de recursos humanos nas próprias empresas, com vistas a interagir em redes tecnológica e economicamente mais dinâmicas.

Para Florida (2000), a presença de capital criativo ou de "talentos" em uma regiấo tenderia a favorecer a expansão de indústrias de alta tecnologia 
e valor agregado, contribuindo ao desenvolvimento regional. Com base em uma ampla investigação empírica realizada em diferentes cidades nos Estados Unidos, o autor argumenta que empresas de alta tecnologia seriam, hoje, atraídas pela disponibilidade de capital criativo em uma regiáo, compreendendo, por exemplo, profissionais de tecnologia e inovação, de artes e cultura, de gestáo e negócios e de educação. Esse tipo de empresa dependeria de recursos humanos com capacidade não apenas de criar inovaçôes, mas também de transformar essas inovações em novas oportunidades de negócios e em circuitos comerciais, requerendo diversidade e interaçáo entre talentos e habilidades. Esse capital tenderia a ser atraído para cidades com maior tolerância ao novo e com vida social mais intensa, possibilitando o florescimento de sua criatividade. Isso ocorreria porque esses trabalhadores poderiam escolher entre oportunidades de emprego, com a possibilidade de optar por locais que lhes parecessem atraentes para viver e trabalhar bem ${ }^{4}$.

Ao abordar as relaçóes entre universidade e indústria na América Latina, Balbachevsky (2010) chama a atenção para a necessidade de interação entre esses agentes, como mecanismo institucional para o avanço de novas áreas do conhecimento, como a nanotecnologia, a biotecnologia e as tecnologias da comunicação e informação (todas proximamente relacionadas às indústrias petrolífera e de construção naval):

Nessas áreas, a produção do conhecimento depende da mobilização de grupos de pesquisa heterogêneos, tanto do ponto de vista cognitivo, como do ponto de vista de sua inserção institucional. Sem cooperação e coordenação entre organizações tão díspares como a academia, hospitais, laboratórios governamentais, agências internacionais, agências regulatórias, e, inclusive, empresas dados cruciais não circulam, as competências não se complementam e o conhecimento produzido é de pior qualidade. (BALBACHEVSKY, 2010, p. 5).

Oliveira e Carvalho (2008) mostram, a partir de ampla pesquisa empírica sobre a realidade de Portugal, que empresas e universidades reagiriam diferentemente aos novos estímulos institucionais relacionados à reconstrução de políticas de ensino superior, de ciência e tecnologia e industrial daquele país.

4 Por exemplo, Austin e Seattle teriam disponibilizado amenidades recreativas, tais como ciclovias, trilhas para mountain bike, parques e áreas de lazer, acessibilidade à água para remo e vela e novos circuitos musicais. atraindo jovens talentos que se orientam pela abertura cultural e diversidade. As cidades estariam entre os líderes nacionais em crescimento inteligente e desenvolvimento sustentável (Florida, 2000). 
As autoras constatam que certo acúmulo de conhecimentos na empresa seria condição básica para a sua inserção em redes de inovação, chamando a atenção para o fato de que, no caso de economias de desenvolvimento intermediário (como Portugal), seria mais realista falar-se em espaços ou redes de inovação em lugar dos sistemas de inovação que se originam no contexto de países desenvolvidos.

Ademais, estudos sobre a recente realidade brasileira chamam a atenção para as novas possibilidades e arranjos para inovação nesse novo contexto criado pela exploração do pré-sal, pois, como conclui Silva (2011, p. 28-29):

Há, contudo, uma tímida, mas nítida desconcentração geográfica e a possível consolidação de novos polos de desenvolvimento científico e tecnológico de ponta nesse setor [...]. É de se esperar, portanto, que o modelo de parceria estabelecido entre o Cenpes-Petrobras e a Coppe-UFRJ seja replicado ou observado como referência exitosa de nosso país, capaz de guiar os novos arranjos locais que, além de possibilitar acesso às diversas oportunidades e recursos emergentes, como aqui foi demonstrado, promovam desenvolvimento inclusivo e intensivo em conhecimento.

Ao explorar a ideia de ruptura nas dinâmicas atuais de desenvolvimento, esses estudos e argumentos oferecem, portanto, indicaçóes sobre capacidades e habilidades dos agentes produtivos em identificar e mobilizar recursos importantes para as atividades de criação de conhecimentos e inovação, reconhecendo-se esforços em construir redes/espaços de inovação que vão além da esfera local ou territorial. Nesse sentido, a capacidade de inovação poderia ser captada por indicadores como aglomeração de empresas, uso de recursos humanos qualificados e interação entre universidade e indústria.

\section{O novo contexto da indústria naval e o polo de Rio Grande}

A indústria de construção naval experimenta, hoje, uma impressionante expansão da produção conjugada com enorme esforço do país em criar conhecimentos específicos, tecnologias e inovaçóes que permitam atender aos requisitos de exploração das riquezas da camada pré-sal. Há certo consenso na literatura especializada recente (COSTA; PIRES; LIMA, 2008; AZEVEDO, 2009; LACERDA, 2003; LIMA; VELASCO, s.d.; NEGRI, 2010; SANT'ANNA, 2010; SILVA, 2011) de que o desenvolvimento dessa indústria depende da criaçáo de mecanismos adequados de financiamento às atividades de pesquisa e desenvolvimento, da formação de mão de obra 
qualificada na área e do estímulo à interação universidade-empresa. Isso permitiria não somente enfrentar os desafios tecnológicos da exploração do pré-sal, mas também um "choque de competitividade" nessa indústria, viabilizando sua inserção no mercado internacional. Ademais, caberia chamar a atenção para o fato de que a indústria de construção naval caracteriza-se por um lento processo de inovação de produto, sendo a inovação de processo - em especial, logística - de enorme relevância para a sua competitividade e elevação da produtividade.

Para uma perspectiva de crescimento de longo prazo dessa indústria, torna-se crucial a inserção competitiva do país no mercado internacional. $\mathrm{Na}$ década de 1970, o Brasil chegou a ser o segundo maior produtor mundial de embarcações, mas declinou nos anos 1980 e 1990. O país não criou competência tecnológica para acompanhar o mercado mundial de construção naval, conquanto fosse favorecido pela situaçáo geográfica e ambiental e detivesse longa trajetória nessa indústria. $\mathrm{O}$ ambiente protegido e de pouco estímulo à produtividade, ao desenvolvimento tecnológico e ao gasto em $\mathrm{P} \& \mathrm{D}$ que se encontrava no Brasil contrastava com a experiência de países como Coreia do Sul, Japão e China (hoje principais produtores mundiais de embarcaçóes), que investiram em inovação para o desenvolvimento dessa indústria (LACERDA, 2003). Desde o final da década 1990, encomendas da Petrobras têm reanimado a construção naval no País, ganhando impulso ao final dos anos 2000 (NEGRI, 2010).

Em âmbito internacional, o setor de construçáo naval mostra-se bastante dinâmico e competitivo, a despeito de haver poucos países realmente expressivos nessa indústria (somente a China e a Coreia do Sul representam 67\% da produção mundial). Na década de 1980, a Europa liderava a produção mundial, perdendo na década seguinte essa posição para o Japão. Nos anos 2000, a Coreia do Sul assume a liderança mundial, cedendo o lugar para à China nos anos 2010. O mercado internacional apresenta enorme demanda por embarcaçóes e plataformas marítimas, considerando-se que boa parte das trocas comerciais entre países é transportada por navios nos oceanos (petróleo, minérios, grãos, carga em contêiner) e que os preços e interesse na exploração do petróleo são crescentes, inclusive a exploração offshore. Caberia chamar a atenção para o caráter estratégico assumido pelas redes de colaboração e de inovação nessa indústria, como nas experiências da Finlândia, da Noruega, dos Estados Unidos e da Coreia do Sul. 
O mercado interno também se modifica, criando-se novas e expressivas demandas a essa indústria. Como antes mencionado, a identificação de jazidas de petróleo e gás natural, em condiçôes de exploração comercial imediata, na camada geológica do pré-sal da costa marítima brasileira criou uma nova e expressiva demanda interna por embarcaçóes e por plataformas marítimas, com vistas a extração, armazenamento, processamento e transporte desses recursos naturais. Porém, trata-se de condiçôes ambientais (profundidade, salinidade, corrosão, pressão, temperatura, luminosidade, distância da costa) e de produtos com características distintas daquilo que o país costuma explorar (tipo de óleo mais pesado e ácido), o que requer não apenas a expansão da capacidade produtiva, mas sobretudo novos conhecimentos para acessar e transformar esses recursos energéticos. Isso envolve amplo conjunto de novos conhecimentos e funçôes produtivas: precisão sobre dimensóes e características das jazidas, para transformar incertezas em riscos econômicos calculáveis; ajustes nas refinarias preparadas para processar óleo leve e "doce"; inovaçóes em logística de pessoal e de materiais, para adequação às maiores distâncias e volume de produção do pré-sal; novos tipos de plataformas e de sondas de perfuração adequadas às novas condiçóes ambientais; soluções aos riscos ambientais em face das pressóes de mercado e de movimentos sociais; novas condiçóes e patamares de produção siderúrgica; desenvolvimento das chamadas "navipeças". Tudo isso envolve inovação em diferentes setores e atividades produtivas.

A partir de meados dos anos 2000, a indústria de construção naval depara-se, no Brasil, com um novo conjunto de encomendas, especialmente da Petrobras/Transpetro, embora outros clientes venham ampliando suas demandas, como a Vale do Rio Doce e a empresa venezuelana PDVSA. A indústria naval do país tem atendido encomendas de diferentes áreas, destacando-se a produção de plataformas de produção de petróleo e de sondas de perfuração do subsolo marítimo, a construção de navios petroleiros, a construção de navios de apoio marítimo, a construção de porta-contêineres e navios graneleiros (transporte de cabotagem) e a construção de embarcaçóes para navegação fluvial (em especial, transporte de passageiros). Em 2011, são mais de 400 empreendimentos de construçáo naval em curso ou previstos nos estaleiros brasileiros: 19 plataformas de produção de petróleo, 30 sondas de perfuração, 30 navios de apoio marítimo, 39 navios petroleiros, entre outros contratos. Estimam-se (SANT'ANNA, 2010) investimentos da ordem de R $\$ 378$ bilhôes em petróleo e gás, no período de 2011 a 2014, no Brasil. 
Essas novas demandas quantitativas e qualitativas contam com incentivos governamentais que buscam distanciar-se do antigo modelo de substituição de importaçôes. O governo (muitas vezes, em colaboração com a Petrobras) modifica ou elabora regulamentos e instrumentos de incentivo não apenas à expansão da capacidade instalada, mas também à formação de recursos humanos e à pesquisa, desenvolvimento e inovação. Esse movimento envolve diferentes formas de parcerias entre indústria e institutos de pesquisa e universidades, com destaque para o Adicional ao Frete para Renovação da Marinha Mercante (AFRMM), que dá origem ao Fundo da Marinha Mercante (FMM), o Programa de Renovaçáo da Frota de Apoio Marítimo (Prorefam I e II), o Programa de Modernização da Frota de Petroleiros (Promef I e II), o Cartão BNDES para Navipeças, o Programa de Mobilização da Indústria Nacional de Petróleo e Gás (Prominp), os Fundos Setoriais (CT - Aquaviário; CT - Petro) e o Regime Tributário para Incentivo à Modernizaçáo e à Ampliação da Estrutura Portuária (Reporto), entre outros.

Esses estímulos refletem-se em expressivo aporte de recursos financeiros para as indústrias petrolífera e naval, orientando-se, muitas vezes, pelo foco em redes de inovação em lugar da simples expansão da grande empresa isolada e da importação de pacotes tecnológicos. Por exemplo, instrumentos como os fundos setoriais e o cartão BNDES voltam-se ao desenvolvimento tecnológico de pequenas empresas de "navipeças". No caso dos fundos, por exemplo, é privilegiado o financiamento de redes de pesquisa e inovaçáo, em lugar da grande empresa isolada. Outra novidade é o Prominp, que formou 43 mil trabalhadores até o ano de 2010, de soldadores a engenheiros, incentivando parcerias entre empresas e universidades, escolas técnicas e institutos de educação. Nesse sentido, a FINEP publicou em 2010 dois editais (R \$ 130 milhôes) para o desenvolvimento de soluçôes tecnológicas para a exploração do pré-sal, mediante redes de colaboração entre empresas da cadeia produtiva e instituiçôes científicas e tecnológicas.

A indústria brasileira tem reagido positivamente aos incentivos governamentais e de mercado, de modo que no ano de 2010 constituíram-se três importantes polos de construçáo naval no país, considerando-se o volume de produção e o nível de emprego: Rio de Janeiro (64 construçóes em execução em 2010; 25 mil empregos diretos), Pernambuco (23 construçôes; 10,5 mil empregos) e Rio Grande do Sul (9 construçóes; 5,5 mil empregos). Os 
estaleiros do país passaram de cerca de 1900 empregos diretos, no ano de 2000, para cerca de 56.000, no ano de 2010; os desembolsos do FMM aumentaram de $\mathrm{R} \$ 300$ milhóes, em 2001, para R \$ 2,6 bilhóes no ano de 2009. Considerando-se o emprego na cadeia produtiva, estima-se um total de 283.000 empregos no ano de 2010 (SINAVAL, 2011). Diferentes tipos de experiências de interação universidade-indústria decorrem desses estímulos de mercado e governamentais. Como ilustraçáo, pode-se referir o núcleo tecnológico da Petrobras no Parque Tecnológico da UFRJ, o Instituto de Pesquisas Tecnológicas da USP, a UNESPetro, o Centro de Pesquisa e Desenvolvimento da Petrobras e, como será adiante detalhado, a Rede de Inovação para a Competitividade da Indústria Naval e Offshore (RICINO).

O polo de construção naval localizado na cidade de Rio Grande (Sul do estado do Rio Grande do Sul) e suas repercussóes sociais em termos da capacidade de inovação dos agentes produtivos é uma expressão desse novo momento das indústrias naval e petrolífera no Brasil. No período entre 2003 e 2005, houve na cidade um primeiro esforço de constituição de um polo naval voltado para a construção de embarcaçóes. Porém, a expansão mais significativa dessa indústria ocorre a partir de 2008, com encomendas da Petrobras de plataformas de exploração petrolífera. O cluster naval de Rio Grande abrigava, em 2011, os estaleiros Ecovix e Quip, e estavam em processo de implantaçáo outros dois: a EBR - Estaleiros do Brasil S/A e o Estaleiro Wilson, Sons Rio Grande. Em 2010, o Estaleiro Quip (consórcio formado por Queiroz Galvão, Ultratec e Iesa) ocupou-se da construção da plataforma marítima semissubmersível de extração de petróleo P-55 (módulos de processos) e da plataforma P-63. O Ecovix ocupou-se, em 2010, da construção de oito cascos para a P-63 e de um bloco de processos para a P-55. A EBR (subsidiária da Setal Óleo e Gás) seria implantada no município de São José do Norte, vizinho a Rio Grande. O estaleiro volta-se para a construção de plataformas marítimas e de embarcaçóes de apoio à exploraçáo de petróleo. Estimava-se a criação de 5 mil empregos diretos, envolvendo investimentos de US\$ 420 milhóes, com financiamento do FMM e incentivos ficais do governo estadual. O Estaleiro Wilson, Sons Rio Grande envolve investimentos de US\$ 140 milhôes do FMM, com previsão de implantação de um centro de treinamento de recursos humanos para atender a demanda do estaleiro. Sua produção volta-se para embarcaçôes de apoio marítimo. As encomendas desses estaleiros sáo realizadas pela Petrobras. 
Caberia referir, em resumo, que a presença desses estaleiros tem representado enormes efeitos econômicos e sociais na região, destacando-se a demanda por novas empresas industriais e de serviços de apoio à produção industrial, assim como recursos humanos qualificados, por exemplo, soldadores e engenheiros. Os recursos humanos disponíveis têm, em geral, formação tradicional, sem as habilidades requeridas aos novos empreendimentos. Essas construçôes requerem um conjunto de inovaçôes e soluçôes tecnológicas que exigem enorme esforço de interação e de circulação de conhecimentos específicos entre os agentes envolvidos. Ademais, esse polo industrial tem envolvido variadas experiências de interação entre universidade e indústria, constituindo redes de relaçóes entre agentes produtivos e institucionais, bem além da dimensão territorial, com vistas ao aproveitamento de recursos relevantes para as atividades de produção de conhecimentos e de inovação. $\mathrm{O}$ curioso é que essas iniciativas constituem-se mesmo em contexto de imaturidade de políticas e instrumentos governamentais, que não caracterizam propriamente um sistema de inovação capaz de empuxar a dinâmica de inovação, e mesmo sem acúmulos regionais ou cultura de inovaçáo nesse tipo de indústria.

Trata-se, pois, de examinar a conduta dos agentes e seus reflexos na capacidade de inovaçáo nessa nova conjuntura industrial. Parece que a recente experiência de Rio Grande ocorre em meio a uma nova perspectiva de desenvolvimento econômico e industrial, relativamente ao passado dessa indústria no país: em lugar da importação de tecnologia, de mercado fechado e protegido e do incentivo à grande empresa isolada, opta-se, respectivamente, pelo esforço em inovar, pela inserção internacional e pelo incentivo a redes de interação entre agentes diversos.

\section{Capacidade de inovação}

A constituição de um polo de construção naval na cidade de Rio Grande envolve, no contexto dos estímulos brevemente caracterizados acima, iniciativas dos agentes que expressam novas capacidades de inovação na economia, tais como a criaçáo e aglomeraçáo de empresas de diferentes setores e tamanhos, formação, atração e uso de trabalhadores qualificados, além da tecedura de redes de interação universidade-indústria.

Um primeiro aspecto dessas mudanças refere-se às tendências verificadas de aquecimento da atividade econômica, de elevação geral do emprego e de 
alteração na distribuição setorial do emprego e das empresas na região, em especial nos municípios de Rio Grande e na cidade vizinha - e polo regional - de Pelotas5. Segundo dados da RAIS/MTE, Rio Grande experimenta, ao longo dos anos 2000, uma importante expansão do emprego formal, e chama a atenção o crescimento do emprego industrial, na construção civil, no comércio e nos serviços. No caso de Pelotas, a expansão do emprego no período é igualmente significativa, em especial nos serviços, no comércio e na construção civil (o emprego industrial não cresce) (ver Tabela 1). Os dados mostram que a presença do polo de construçáo naval leva ao crescimento do emprego industrial e de serviços de apoio à produção industrial, como obras de infraestrutura no porto e soluçóes em logística. Ademais, a circulação de uma nova massa salarial na regiáo cria novas demandas de consumo, aquecendo a atividade em outros setores econômicos, como a construção civil e o comércio.

Tabela I - Evolução do número de empregados por setor de atividade econômica (IBGE) em Rio Grande e Pelotas - 2002, 2006 e 2010

\begin{tabular}{lccccccccc}
\hline & \multicolumn{3}{c}{ Rio Grande } & \multicolumn{3}{c}{ Pelotas } \\
& 2002 & 2006 & 2010 & Variação \% & 2002 & 2006 & 2010 & Variação \% \\
\hline Extrativa mineral & 36 & 56 & 67 & 86 & 118 & 108 & 63 & -47 \\
Indústria de transformação & 3726 & 5423 & 6060 & 63 & 9375 & 8008 & 9054 & -3 \\
Serv. Industr. de util. pub. & 399 & 480 & 598 & 50 & 283 & 323 & 510 & 80 \\
Construção civil & 551 & 1128 & 1583 & 187 & 2478 & 2389 & 4060 & 64 \\
Comércio & 6037 & 7606 & 9572 & 59 & 11170 & 13370 & 18136 & 62 \\
Serviços & 11427 & 13111 & 16115 & 41 & 16488 & 19728 & 26988 & 64 \\
Administração pública & 5683 & 6477 & 4945 & -13 & 8505 & 9710 & 9612 & 13 \\
Agrop., extr. veg., caça e pesca & 1284 & 812 & 919 & -28 & 1387 & 1557 & 1220 & -12 \\
\hline Total & 29143 & 35093 & 39859 & 37 & 49804 & 55193 & 69643 & 40 \\
\hline
\end{tabular}

Fonte: RAIS/MTE, 2011 .

5 Pelotas localiza-se a cerca de $50 \mathrm{~km}$ de Rio Grande, contando com aproximadamente 400 mil habitantes contra cerca de 200 mil, em Rio Grande. 
Para tentar captar essa dinâmica de criação e de aglomeração de empresas relacionadas à construçấo naval, selecionou-se uma amostra de 10 segmentos produtivos em indústria e serviços nos munícios de Rio Grande e de Pelotas (empregando-se a nova classificação de Divisóes CNAE 2.0, criada em 2006) relacionados com a atividade fim do polo naval (Gráfico 1). Desse modo, constata-se tendência de expansão de estabelecimentos nesses segmentos produtivos, apontando para uma possível aglomeração de empresas industriais e de serviços com eixo na construção naval. Caberia chamar a atenção para o crescimento do número de estabelecimentos em Pesquisa e Desenvolvimento e em Atividades Profissionais, Científicas e Técnicas, que envolvem conhecimentos altamente especializados. Quanto ao tamanho das empresas, observa-se o crescimento mais expressivo de pequenas e microempresas (até 49 empregados). Estudos chamam a atenção (MAILLAT, 2002; RAMELLA; TRIGILIA, 2009) sobre as externalidades, especialmente dinâmicas de interação e trocas de conhecimentos, decorrentes desse tipo de aglomeração, envolvendo um caráter ativo dos agentes empresariais com vistas a captar recursos relevantes para suas atividades.

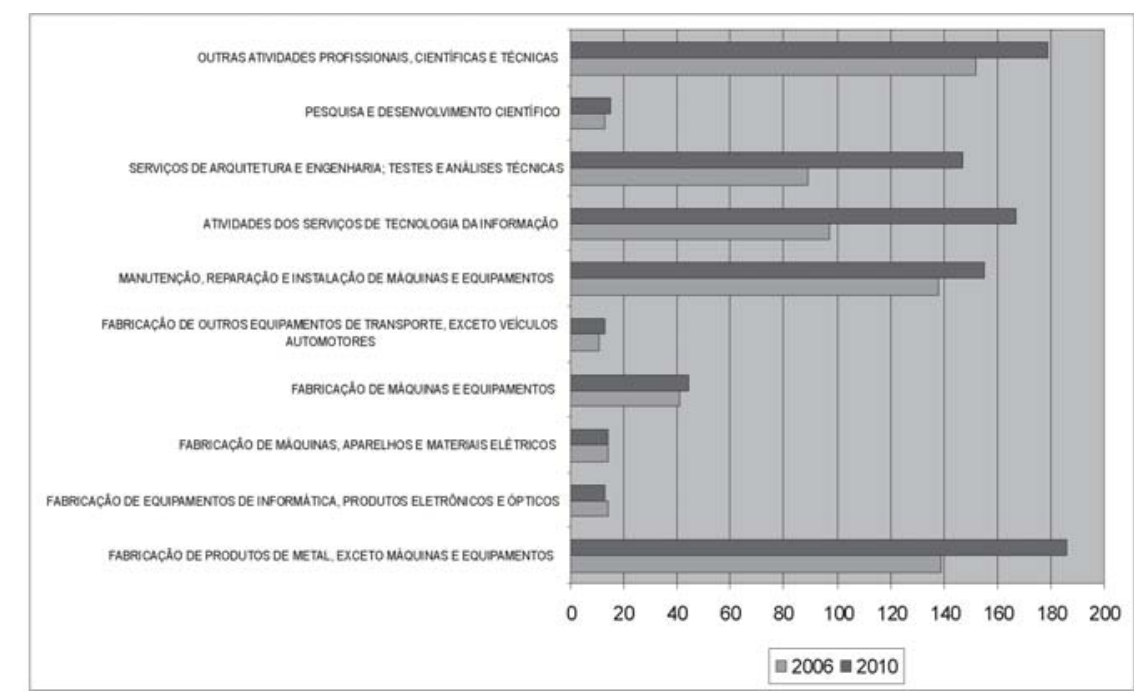

Gráfico I - Evolução do número de estabelecimentos em divisões CNAE 2.0 selecionadas nos municípios de Rio Grande e Pelotas - 2006/20 I0

Fonte: RAIS/MTE, 2011. 
No que se refere aos recursos humanos, os dados da RAIS (Gráfico 2) mostram uma flagrante elevação da escolaridade dos empregados nos municípios de Rio Grande e Pelotas nos anos 2000, o que expressa ganhos na capacidade de inovação regional (ARBIX, 2010; SALERNO, 2010). A tendência indicada nos dados é de crescimento mais rápido do número de empregados nos níveis de ensino médio e superior do que o verificado no ensino fundamental. Outro aspecto relevante refere-se ao crescimento de ocupaçóes com qualificaçóes relativamente elevadas, como gerentes, profissionais das ciências exatas, físicas e biológicas, profissionais de ensino e técnicos de nível médio em ciências e administração. Na hipótese de Florida (2002), a presença desse tipo de profissionais seria crucial para o avanço das atividades de conteúdo tecnológico e inovador.

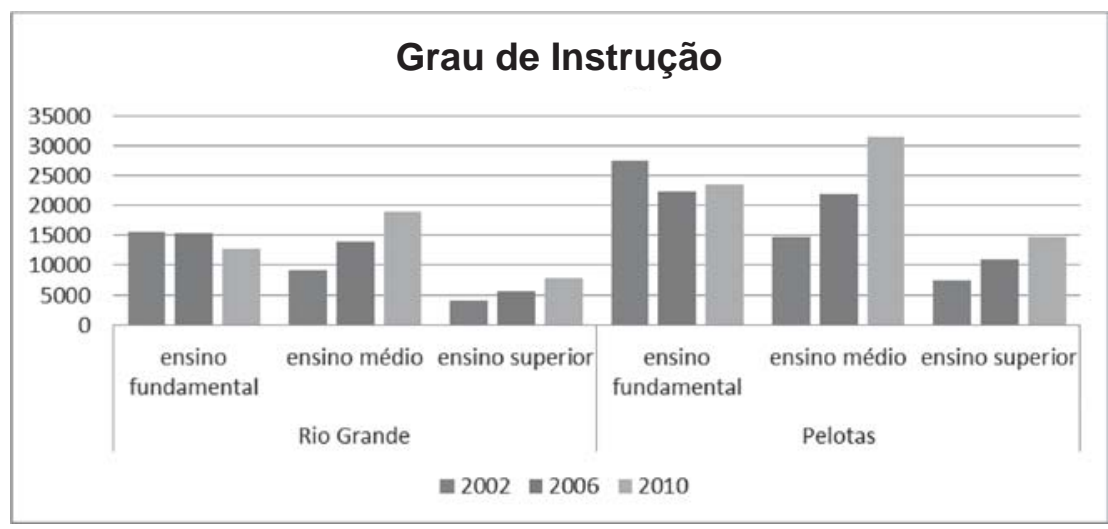

Gráfico 2 - Evolução do número de empregados por grau de instrução emRio Grande e Pelotas - 2002/2006/2010

Fonte: RAIS/MTE, 2011 .

O novo polo industrial tem, também, provocado diferentes reaçóes de universidades do estado (como UFRGS, UFPel, UCPel e FURG), cabendo identificar, ainda que preliminarmente, características dessas respostas, os recursos mobilizados e os interesses que as motivam (ver Quadro 1). Essa abordagem se aproxima de resultados apresentados em estudos recentes que indicam a relevância dessas interaçóes na capacidade de inovação (ARBIX, 2010; BALBACHEVSKY, 2010; SILVA, 2011). Em Porto Alegre, na Universidade Federal do Rio Grande do Sul (UFRGS), há um laboratório credenciado pela 
Petrobras (um dos três existentes no país), resultante de parceria entre a empresa e o Instituto de Geociências. Além disso, há empresas de alta tecnologia na área em incubadoras da universidade. No caso da UFRGS, as suas respostas parecem estar relacionadas com a expertise em geologia, que atrai o interesse de agentes como a Petrobras.

Outra resposta ao polo naval é formulada pela Universidade Federal de Pelotas (UFPel); a universidade criou, em 2009, dois novos cursos de graduaçáo aplicados às indústrias naval e petrolífera: Engenharia de Petróleo e Engenharia Geológica. Esse tipo de esforço, como no caso da FURG, não somente requer incentivos financeiros obtidos pelas universidades fora da regiáo (por exemplo, REUNI), como também implica na captação de recursos humanos altamente especializados (professores, cientistas, pesquisadores), atraídos para a região. Caberia referir ainda os esforços da Agência Científica e Tecnológica da UFPel no sentido de promover estudos e parcerias com setor empresarial aplicados ao polo naval. Nesse caso, a reação da universidade parece relacionar-se com o seu foco na expansão de atividades de ensino e pesquisa, no contexto do Reuni, na medida em que a universidade duplicou rapidamente a capacidade de matrículas na segunda metade dos anos 2000 (passou de cerca de 12 mil alunos, em 2005, para cerca de 25 mil matrículas, em 2010). Isso absorve energias da instituição no sentido de captar recursos e de planejar tal expansão.

Também na cidade de Pelotas, está em fase de criação o Tecnosul (Parque Tecnológico da Universidade Católica de Pelotas - UCPel), que hospedará empresas voltadas para indústria naval fina, entre outros setores de alta tecnologia. A iniciativa conta com amplo apoio do governo local. Isso implica na identificação e atraçáo para a regiáo de empresas de alta tecnologia que possam contribuir com o desenvolvimento do polo naval. Um fator decisivo para a constituição do parque parece ser a relação da universidade com a PUCRS, que detém enorme expertise com o Tecnopuc. Isso pode ter significado importante recurso externo e motivação para esse tipo de empreendimento 


\begin{tabular}{|c|c|c|}
\hline Universidade & Iniciativa & Motivo \\
\hline $\begin{array}{l}\text { Universidade Federal } \\
\text { do Rio Grande do Sul - } \\
\text { UFRGS }\end{array}$ & $\begin{array}{l}\text { Parcerias com Petrobras (Laboratórios e } \\
\text { consultorias); Novo curso: Engenharia } \\
\text { de Energia }\end{array}$ & Expertise em Geologia; área metropolitana \\
\hline $\begin{array}{l}\text { Universidade Federal de } \\
\text { Pelotas - UFPel }\end{array}$ & $\begin{array}{l}\text { Novos cursos: Engenharia de Petróleo; } \\
\text { Engenharia Geológica }\end{array}$ & $\begin{array}{l}\text { Expansão ensino e pesquisa/ Reuni; } \\
\text { desenvolver novas áreas tecnológicas }\end{array}$ \\
\hline $\begin{array}{l}\text { Universidade Católica de } \\
\text { Pelotas - UCPel }\end{array}$ & Parque Tecnológico: Tecnosul & Laços com PUCRS/ Tecnopuc \\
\hline $\begin{array}{l}\text { Universidade Federal de } \\
\text { Rio Grande - FURG }\end{array}$ & $\begin{array}{l}\text { Rede nacional: RICINO; Parque } \\
\text { Tecnológico: Oceantec; Complexo } \\
\text { turístico e de pesquisa: Oceanário } \\
\text { Brasil; Novos cursos: Engenharia de } \\
\text { Automação; Engenharia Mecânica } \\
\text { Naval }\end{array}$ & $\begin{array}{l}\text { Proximidade com o polo naval; expertise } \\
\text { em áreas ambiental e de mares e } \\
\text { oceanos }\end{array}$ \\
\hline
\end{tabular}

Quadro I - Iniciativas relacionadas à indústria naval e do petróleo de universidades selecionadas do Rio Grande do Sul

Fonte: Pesquisa de campo e documental - Porto Alegre/ Rio Grande/ Pelotas, 2011.

Chama a atenção a experiência da Fundação Universidade Federal do Rio Grande (FURG), que não apenas iniciou, em 2010, as atividades dos novos cursos de graduação em Engenharia de Automação e Engenharia Mecânica Naval, mas também dá andamento a diferentes empreendimentos de produção de conhecimentos específicos, como o Oceantec (Parque Científico e Tecnológico do Mar) e o Oceanário Brasil (parque turístico e de estudos e pesquisas sobre oceanos). Essas novidades ocorrem em meio à captação de recursos no âmbito do Reuni - Ministério da Educaçáo - e do envolvimento da universidade na RICINO.

A RICINO é uma rede de colaboração entre indústria, instituições de ensino e pesquisa e governo; foi criada no ano de 2009, com o propósito de contribuir para o desenvolvimento tecnológico da indústria de construção naval do país e sua sustentabilidade ambiental e inserção internacional. Essa rede origina-se do esforço de lideranças acadêmicas que perceberam a janela de oportunidade envolvida na indústria naval, assumindo o papel de criaçáo de iniciativas institucionais. A criação da rede parte do reconhecimento das limitaçóes da indústria nacional frente aos recentes desenvolvimentos e oportunidades em âmbito internacional, da identificação de diferentes fontes de 
financiamento hoje disponíveis no país para a inovação (como o Prominp e os Fundos Setoriais) e do mapeamento de diversas iniciativas isoladas de empresas desse setor produtivo e de instituiçóes de ensino e pesquisa. Trata-se de uma iniciativa conjunta da Sociedade Brasileira de Engenharia Naval (SOBENA), do Sindicato Nacional da Indústria da Construção e Reparação Naval e Offshore (SINAVAL), do Sindicato Nacional das Empresas de Navegação Marítima (SYNDARMA) e do Centro de Excelência em Engenharia Naval e Oceânica (CEENO), passando a agregar outros atores institucionais. É formada, inicialmente, por três núcleos temáticos (Núcleo de Tecnologia da Construção e Reparação Naval e Offshore; Núcleo de Projeto de Embarcações e Sistemas Offshore; e Núcleo de Cadeia Produtiva da Indústria Naval e Offshore) e dois núcleos regionais (Núcleo Regional Recife; e Núcleo Regional Rio Grande).

O Núcleo Regional de Rio Grande (NRRG) tem sede na FURG ${ }^{6}$. Entre as principais iniciativas, pode-se destacar a implantação do Oceantec, com o propósito de potencializar a inovaçáo tecnológica das empresas da regiáo. Seu mecanismo seria estabelecer novas relaçóes entre instituições de pesquisa e empresas, envolvendo a sociedade local, governo e empresas da regiáo e dos demais polos de construção naval do país. O Parque orienta-se por três eixos científico-tecnológicos: a) a construção naval, focalizando o desenvolvimento de tecnologias voltadas à construção de embarcaçôes e plataformas ambientalmente sustentáveis; b) atividades offshore, voltando-se para o desenvolvimento de equipamentos, tecnologias e arquitetura e engenharia de megaestruturas, com vistas à exploração mineral na plataforma continental e futura exploração de fontes alternativas de energia no mar; e c) sustentação logística, desenvolvendo soluçóes capazes de viabilizar econômica e ambientalmente os projetos desenvolvidos no mar.

Outra ação da rede, em execução pela FURG, é a implantação do Centro Avançado em TI na Construçáo Naval e Offshore. O centro integra laboratórios e grupos de pesquisa dedicados às áreas de TI e automação que são consideradas críticas para a competitividade da indústria de construçáo naval. Ele deverá contribuir com os demais polos do país, a partir de Rio Grande.

6 O NRRG é coordenado por professor-pesquisador da FURG, sendo integrado por FIERGS, ABDI, Estaleiro Wilson, Sons, Petrobras, QUIP, Engevix, IFRS, IFSul, UFRGS, UFPel, Prefeitura Municipal de Rio Grande, Secretaria Estadual de Ciência e Tecnologia do RS. Superintendência do Porto de Rio Grande, SEBRAE, SIMECS, BNDES e Prefeitura Municipal de Pelotas. 
Essa iniciativa tem como parceiros estratégicos FURG, COPPE/UFRJ, IPT/ USP, UFPE e UFRGS. O Centro Avançado de Formação em Tecnologias de Solda, em execução pela FURG e pelo IFSul, visa à formação de especialistas em tecnologia de solda, propondo-se a abranger tecnologias no estado da arte em nível mundial. A parceria volta-se, também, à interação com os demais polos de construção naval do país. São considerados parceiros estratégicos para o desenvolvimento desses conhecimentos: Centro de Soldagem do SENAI, COPPE/UFRJ, IPT/USP, UFPE, Escolas Técnicas dos estados que hospedam estaleiros de grande porte. Ademais, a FURG é considerada parceira estratégica em outras ações da rede nos seus demais núcleos, como na implantação, pelo COPPE/UFRJ, do Centro de Tecnologia da Construção Naval e Offshore e na implantação, pela UFRJ, do Centro Avançado de Formação de Técnicos em Construção Naval.

As respostas criadas pela FURG ao polo naval parecem relacionar-se com dois aspectos importantes: primeiro, a proximidade com o polo e o Porto de Rio Grande, que podem significar certo acúmulo de conhecimentos tácitos, indisponíveis em outras localidades; segundo, a expertise da universidade na área de mares e oceanos e na área ambiental (a FURG é referência em pós-graduação e pesquisa em oceanografia, oceanologia e educação ambiental). Essas credenciais são atestadas pela inserção da FURG em várias redes e consórcios de PD\&I associados ao estudo dos mares, como CEMBRA, Polo Sul da Amazônia Azul, Oceanário Brasil, Redes Temáticas Petrobras/CENPES e CEENO. Ademais, a universidade orienta-se para a captação e troca de conhecimentos em âmbito nacional.

Portanto, o que se tem são novos esforços e iniciativas dos agentes que se refletem em capacidades inovativas, como criação e aglomeração de empresas, valorização de qualificaçóes e novas ocupações aos recursos humanos e esforços de interação entre universidades e mercado. Nesse particular, cabe destacar as diferentes respostas das universidades (mais ou menos agressivas), segundo uma leitura dos agentes sobre as potencialidades já existentes e as oportunidades em circulação no ambiente. As relações das universidades envolvidas vão além da dimensão territorial ou regional, constituindo-se pelo interesse em produzir novo conhecimento e inovação, no contexto de um novo paradigma de desenvolvimento econômico e social. Isso implica na tecedura de redes de relaçóes institucionais que visam à busca de recursos importantes onde estiverem 
disponíveis. Outro aspecto é o de que essas respostas das universidades e suas relações com a indústria que emergem a partir da oportunidade do polo naval de Rio Grande não têm relação com a existência prévia de uma estrutura de governança regional.

\section{Considerações finais}

O caso em discussão no presente artigo oferece indicações sobre a conduta dos agentes produtivos em novo contexto de desenvolvimento experimentado no país, com enfoque para os efeitos da constituição de um polo industrial em termos da expansão da capacidade de inovação. Com base em estudos recentes sobre inovaçáo, em especial no contexto de países em desenvolvimento (ARBIX, 2010; ARIFFIN; FIQUIREDO, 2008; NEGRI; SALERNO, 2005; SALERNO, 2010), o artigo tentou expressar essa capacidade por meio da demonstração do que ocorre, na regiáo em estudo, em relação à aglomeração de empresas, à qualificação dos recursos humanos e às interaçôes universidade-empresa. Nesse sentido, o esforço seria captar possíveis dinâmicas de inovaçáo incremental que escapam às métricas "tradicionais" de apreensáo do fenômeno, que se voltam para a inovação radical de produtos. Como antes referido (COSTA; PIRES; LIMA, 2008; LACERDA, 2003; NEGRI, 2010; SANT'ANNA, 2010), a indústria de construção naval seria caracterizada mais por inovaçôes incrementais de processo e logística, restando inadequados os indicadores de inovaçáo comumente empregados.

Embora os dados antes discutidos sejam ainda bastante preliminares, há, desse prisma, indicaçóes sobre tendências em torno da ideia de criação de conhecimentos especializados e de inovação nessa indústria: novas empresas são constituídas, recursos humanos mais qualificados são utilizados e universidades são envolvidas nessa nova dinâmica produtiva. Como sugerido em estudos sobre o tema (CASTELLS, 1999; MAILLAT, 2002; RAMELLA; TRIGILIA, 2009), os agentes produtivos parecem empenhar-se em tecer redes de colaboração e interação, com vistas a acessar recursos relevantes (financiamento, informação, conhecimento específico, mercados), no contexto de incentivos governamentais e de demandas de mercado, para a criaçáo de conhecimento especializado e de inovação.

Parece, portanto, haver um esforço ativo dos agentes produtivos em criar novos conhecimentos que contribuam para o desenvolvimento dessa indústria 
no país. Isso é bastante diferente do antigo modelo de desenvolvimento amparado na importação de pacotes tecnológicos, no uso de mão de obra não qualificada e no incentivo à grande empresa isolada. Como referido, estudos recentes têm demonstrado a relevância de pensar-se o papel dos agentes empresariais e científicos na constituiçáo de redes de curto e de longo alcance para a produção de inovação (RAMELLA; TRIGILIA, 2009; OLIVEIRA; CARVALHO, 2008), assim como o caráter transdisciplinar e interinstitucional da criação de conhecimentos e inovaçóes na sociedade atual (BALBACHEVSKY, 2010).

Finalmente, caberia chamar a atenção para a importância de investigaçóes futuras que venham a explorar náo apenas os diversos arranjos e institucionalidades de governança dos diferentes interesses entre os agentes envolvidos na inovação (como é o propósito da ampla literatura sobre meios inovadores), mas também sobre como se constituem e se realizam esses interesses no atual paradigma de desenvolvimento econômico e social. Isso seria particularmente relevante em contextos - como o discutido neste artigo - em que náo existe cultura de inovação ou instituiçóes articuladas (sistemas de inovação) para oferecer um quadro de referências para os atores. Essa poderá ser uma promissora agenda sociológica.

\section{Referências}

ARBIX, G. Caminhos cruzados: rumo a uma estratégia de desenvolvimento baseada na inovação. Novos Estudos - CEBRAP, n. 87, p.13-33, julho 2010.

ARIFFIN, Norlela; FIGUEIREDO, Paulo. Globalization of innovative capabilities: evidence from local and foreign firms in the elestronics industry in Malaysia and Brazil. Science, Technology \& Society, v. 11, n. 1, p.191-227, 2006.

BALBACHEVSKY, Elizabeth. Entraves e incentivos para o desenvolvimento de sinergias entre universidade e sociedade na produção do conhecimento: a experiência da América Latina. In: $34^{\circ}$ ENCONTRO DA ANPOCS, 2010. Anais... Caxambu: Anpocs, 2010.

BARROS, Octavio; GIAMBIAGI, Fabio (Org.). Brasil globalizado: o Brasil em um mundo surpreendente. Rio de Janeiro: Campus/Elsevier, 2008.

CASTELLS, Manuel. A sociedade em rede. 2. ed. São Paulo: Paz e Terra, 1999.

CASTRO, Ana Célia et al. (Org.). Brasil em desenvolvimento: economia, tecnologia e competitividade. Rio de Janeiro: Civilização Brasileira, 2005. 
Agentes produtivos e desenvolvimento: polo naval e capacidade de inovação no Rio Grande do Sul | Sandro Ruduit Garcia

COSTA, Ricardo; PIRES, Victor Hugo; LIMA, Guilherme Penin Santos de. Mercado de embarcaçốes de apoio marítimo às plataformas de Petróleo: oportunidades e desafios. BNDES Setorial, Rio de Janeiro, n. 28, p. 125-146, set./2008.

FLIGSTEIN, Neil. Social skill and the theory of fields. Sociological Theory, v. 2, n. 19, p. 105-25, jul. 2001.

FLORIDA, Richard. Competing in the age of talent: quality of place and the new economy. Report, january 2000. Disponível em: < http://burgosciudad21.org/adftp/Florida.pdf >. Acesso em: ago. 2012.

GABRIELLI-DE-AZEVEDO, José Sergio. Esboço de um marco conceitual para a análise da indústria do petróleo, pré-sal e desenvolvimento. In: GIAMBIAGI, F.; BARROS, O. (Org.). Brasil pós-crise: agenda para a próxima década. Rio de Janeiro: Elsevier, 2009. p. 247-266.

GIAMBIAGI, F.; BARROS, O. (Org.). Brasil pós-crise: agenda para a próxima década. Rio de Janeiro: Elsevier, 2009.

GIDDENS, Anthony. A constituiçáo da sociedade. São Paulo: Martins Fontes, 2003.

A política da mudança climática. São Paulo: Paz e Terra, 2010.

GUIDELLI, N. S.; BRESCIANI, L. P. Qualidade de vida no trabalho e ambiente de inovação: encontros e desencontros no serviço de atendimento ao cliente. Revista Brasileira de Inovaçáo, Rio de Janeiro, v. 7, n. 2, p. 341-365, jul.-dez. 2008.

GUILLÉN, M.; GARCÍA-CANAL, E. The american model of the multinacional firm and "new" multinationals from emerging economies. Academy of Management Perspectives, p. 23-35, may 2009.

KIM, Linsu. Da imitaçáo à inovação: a dinâmica do aprendizado tecnológico da Coréia. Campinas: Editora da Unicamp, 2005.

LACERDA, Sander Magalhães. Oportunidades e desafios da construção naval. Revista do BNDES, Rio de Janeiro, v. 10, n. 20, p. 41-78, dez. 2003.

LIMA, Eriksom Teixeira; VELASCO, Luciano Otávio Marques de. Construçáo naval no Brasil: existem perspectivas? Paper Digitado, s/d.

MAILLAT, Denis. Globalização, meio inovador e sistemas territoriais de produção. Interaçóes: Revista Internacional de Desenvolvimento Local, v. 3, n. 4, p. 9-16, 2002.

NEGRI, J. A.; SALERNO, M. S. (Org.). Inovaçóes, padróes tecnológicos e desempenho das 
firmas industriais brasileiras. Brasília: IPEA, 2005.

NEGRI, João Alberto de (Coord.). Poder de compra da Petrobras: impactos econômicos nos seus fornecedores. Brasília: IPEA/Petrobras, 2010.

OECD - Organization for Economic Co-Operation and Development. Benchmarking IndustryScience Relationships. Paris: OCDE, 2002.

OLIVEIRA, Luísa \& CARVALHO, Helena. Inovação e relações universidade-indústria em países de desenvolvimento intermédio. Journal of Technology Management \& Innovation, v. 3, n. 2, p. 67-85, 2008.

POWELL, W.; SNELLMAN, K. The knowledge economy. Annual Review of Sociology, v. 30, p. 199-220, Feb. 2004.

RAMELLA, F.; TRIGILIA, C. Firms and territories in innovation: lessons from the Italian case. CSES Working Paper Series, v. 55. Ithaca (NY): Cornell University, 2009.

SALERNO, M. S. et al. (Org.). Inovação: estudos de jovens pesquisadores brasileiros. São Paulo: Papagaio, 2010.

SANT'ANNA, André Albuquerque. Brasil é a principal fronteira de expansão do petróleo no mundo. Visáo do Desenvolvimento, BNDES, n. 87, p. 1-8, out. 2010.

SINAVAL. A indústria de construçáo naval e o desenvolvimento brasileiro - 2010. Rio de Janeiro: SINAVAL, 2011. Disponível em: <www.sinaval.org.br>.

SILVA, Marconi A. Inovação no setor de petróleo e gás do Brasil: a parceria CENPES-Petrobras e COPPE-UFRJ. In: 35 ENCONTRO ANUAL DA ANPOCS, 2011. Anais... Caxambu: Anpocs, 2011.

SWEDBERG, R. A sociologia econômica do capitalismo: uma introdução e agenda de pesquisa. In: MARTES, A. C. B. (Org.). Redes e sociologia econômica. São Carlos: EdUFSCar, 2009. p. 161-206.

THERBORN, Göran. Globalizations: dimensions, historical waves, regional effects, normative governance. International Sociology, London, v. 15, n. 2, p. 151-179, jun. 2000.

VELLOSO, João Paulo dos Reis (Coord.). O Brasil e a economia criativa: um novo mundo nos trópicos. Rio de Janeiro: José Olympio, 2008. 
Recebido em: 14.11.2011

Aprovado em: 25.04.2013

\section{Productive agents and development: naval pole and innovativeness in Rio Grande do Sul}

\section{Abstract}

The article attempts to identify new dynamics of economic and social development in Brazil, focusing on government incentives and market the establishment of a pole of naval construction in the city of Rio Grande in the second half of 2000 and the responses of productive agents in terms of the expansion of innovation, translated into externalities created by the spatial clustering of companies, in human resource capacities, and especially initiatives of universities in the state of Rio Grande do Sul. The hypothesis under discussion is that the productive agents tend to respond to new stimuli government and market with the creation of collaborative networks applied to the production of expertise and innovation. Data are derived from interviews with managers shipyards, port and universities, conducted in the first half of 201 I, Rio Grande, Pelotas and Porto Alegre, as well as various secondary sources (documents and statistical bases).

Keywords: Economic development. Innovation. Naval construction industry. 